\title{
Chemical composition, antioxidant potential and cyto-protecting activity of essential oil of Liriodendron tulipifera $\mathrm{L}$. leaves
}

\author{
Anil Kumar Yadav ${ }^{1 \#}$, Sang Ho Kim²\#, Sun Chul Kang ${ }^{1 *}$ \\ 1 : Department of Biotechnology, Daegu University, Kyoungsan, Kyoungbook 712-714, Republic of Korea \\ 2 : Department of Biology Education, Daegu University, Kyoungsan, Kyoungbook 712-714, Republic of Korea
}

\begin{abstract}
Objectives : The present study was under taken to characterize chemical composition, antioxidant and cyto-protecting capacity of essential oil obtained from leaves of Liriodendron tulipifera L.

Methods : Essential oil from the leafof L. tulipifera L. (EOLL) was extracted by hydro-distillation process and further its chemical composition was evaluated by GC-MS analysis. The in vitro antioxidant potential of the EOLL was determined by $\mathrm{DPPH}^{\bullet}, \mathrm{ABTS}^{\bullet+}$, superoxide and nitric oxide free radical scavenging activity using different concentrations in the range of $50-800 \mu \mathrm{g} / \mathrm{mL}$. In addition, cyto-protecting property of the EOLLwas determined by MTT assay on Raw 264.7 macrophage cells challenged with hydrogen peroxide $\left(\mathrm{H}_{2} \mathrm{O}_{2}\right)$.

Results : The result of GC-MS analysis showed presence of 34 volatile compounds, principally germacrene D, spathulenol, and $\alpha$-cadinol in EOLL. The in vitro antioxidant assays of EOLL at the highest used concentration of $800 \mu \mathrm{g} / \mathrm{mL}$ showed 81.62, 84.29, 83.59 and 58.59\% inhibition of $\mathrm{DPPH}^{\bullet}, \mathrm{ABTS}^{\bullet+}$, superoxide, and nitric oxide radicals, respectively. It also showed ferric reducing ability with $1310.04 \mathrm{mM} \mathrm{Fe}$ (II)/g of essential oil. The EOLL at three different concentrations (200, 400 and $800 \mu \mathrm{g} / \mathrm{mL}$ ) protected the cells from $\mathrm{H}_{2} \mathrm{O}_{2}-\mathrm{induced}$ cell damage through scavenging intracellular ROS.

Conclusion : The findings from the study suggest that essential oil isolated from leaves of $L$ tulipifera L. is a potent sources of natural antioxidants, which could be used to treat the diseases associated with oxidative stress condition.
\end{abstract}

Key words : Liriodendron tulipifera L., GC-MS, oxidative stress, MTT assay, antioxidant, cyto-protection.

\section{Introduction}

Oxidation is a key step for generation of energy in aerobic metabolism to fuel biological process. Free radicals such as superoxide radical $\left(\mathrm{O}_{2}{ }^{\circ}\right)$ hydroxyl radicals $\left({ }^{\circ} \mathrm{OH}\right)$ and singlet oxygen $\left({ }^{1} \mathrm{O}_{2}\right)$ are constantly generated as byproduct of metabolism ${ }^{1)}$. Besides endogenous metabolism process, exogenous sources such as ionizing radiations, UV light, and pesticides are also involved in production of highly reactive free radicals ${ }^{2}$. Fortunately, living beings possess an innate antioxidant enzymes defense mechanism including catalase, superoxide dismutase (SOD), glutathione (GSH) and peroxidase, to protect the functional and structural integrity of the biological molecules such as DNA, proteins, and lipids from detrimental effects of $\operatorname{ROS}^{3,4)}$. However, during oxidative stress, which results from imbalance between formation and neutralization of pro-oxidants, antioxidant defence system become insufficient and this oxidative state is sole culprit for the physiological and pathological conditions such as cancer, aging, rheumatoid arthritis, atherosclerosis and neurodegenerative diseases ${ }^{5-9)}$.

In recent years research has been more focused towards to dugout non-toxic and more effective bioactive phyto-chemicals having antioxidant property, to substitute synthetic preservative antioxidants like butylated

\footnotetext{
*Corresponding author : Sun Chul Kang. Department of Biotechnology, Daegu University, Kyoungsan, Kyoungbook 712-714, Republic of Korea

- Tel : +82-53-850-6553 · Fax : +82-53-850-6559 · E-mail : sckang@daegu.ac.kr

\#First author : Anil Kumar Yadav. Department of Biotechnology, Daegu University, Kyoungsan, Kyoungbook 712-714, Republic of Korea

· Tel : +82-53-850-4416 · Fax : +82-53-850-6559 • E-mail : anilyadav.cool@gmail.com

Sang Ho Kim. Department of Biology Education, Daegu University, Kyoungsan, Kyoungbook 712-714, Republic of Korea

· Tel : +82-53-850-6995 · Fax : +82-53-850-6999 ·E-mail : sangkim@daegu.ac.kr

- Received : 23 June 2015 - Revised : 12 July 2015 - Accepted : 12 July 2015
} 
hydroxyanisole (BHA), and butylated hydroxytoluene (BHT), whose applications are circumscribed because of their toxic and/or mutagenic concerns ${ }^{10)}$. In this context, among different kinds of natural substances, essential oils and their components due to their relatively non-toxic nature, acceptance with consumers, and a wide spectrum of biological activity, have received a meticulous attention as a potential source of antioxidants ${ }^{11}$

Liriodendron tulipifera a L. commonly known as tulip tree is a rich source of various biologically active phyto-chemical including sesquiterpene, apophine, and alkaloids which makes it a suitable candidate for pharmacy $^{12,13)}$. The bark of $L$. tulipifera was used by the native Americans as a tonic, stimulant and febrifuge, and likely was used to treat the intermittent fevers associated with malaria ${ }^{14,15)}$. However, there are no such reports about antioxidant activity and oxidative stress healing properties of the essential oil obtained from leaves of $L$. tulipfera. Therefore, the present study was under taken to assess the chemical composition, antioxidant and cyto-protective activity of essential oil obtained from the leaves of $L$. tulipifera (EOLL).

\section{Materials and methods}

\section{1. chemicals and cell line}

DPPH (1,1-diphenyl-2picrylhydrazyl), ABTS (2,2-azinobis -(3ethylthiazoline-6-sulphonic acid), ferric chloride, Griess reagent, nitro blue tetrazolium (NBT), xanthine, xanthine oxidase, 2,4,6-Tris (2-pyridyl) $-s-$ triazine (TPTZ), quercetin, sodium nitroprusside (SNP), $\mathrm{CM}-\mathrm{H}_{2} \mathrm{DCFDA}$ stain, fetal bovine serum(FBS), Dulbeco's modified eagles medium (DMEM), trypsin-EDTA, antibiotics, phosphate buffer saline (PBS) and hydrogen peroxide, were purchased from Sigma-Aldrich (St. Louis, MO, USA). All other reagents used for isolation of essential oil were of highest analytical grade. Raw 264.7 macrophages, obtained from American Type Culture Collection (ATCC), were grown as monolayer in DMEM supplemented with $10 \%$ FBS, and $1 \%$ penicillin-streptomycin at $37{ }^{\circ} \mathrm{C}$ under $5 \% \mathrm{CO}_{2}$ in humidified chamber.

\section{Plant material and isolation of essential oil}

Leaves of $L$. tulipifera were collected from Kyoungsan city of Republic of Korea in August 2012. After air drying, leaves of $L$. tulipifera $(500 \mathrm{~g})$ were grinded and subjected to hydro distillation for $3 \mathrm{~h}$ using a Clevenger type apparatus. The essential oil from the aqueous distillate was extracted by liquid-liquid extraction method using dichloromethane. The essential oil was recovered from dichloromethane layer by drying it in anhydrous sodium sulfate. The obtained essential oil with a yield of $0.27 \%(\mathrm{w} / \mathrm{w})$ was transfer into dark color vial and stored at $4{ }^{\circ} \mathrm{C}$ for further use.

\section{Gas chromatography-mass spectrometry (GC-MS) analysis of EOLL}

Quantitative and qualitative analysis of the EOLL was performed using a GC-MS (Model QP 2010, Shimadzu, Japan) equipped with a ZB-1 MS fused silica capillary column $(30 \mathrm{~cm} \times 0.25 \mathrm{~cm}$ i.d., film thickness $0.25 \mu \mathrm{m})$. For GC-MS detection, an electron ionization system with ionization energy of $70 \mathrm{eV}$ was used. Helium was used as a carrier gas at a constant flow rate of 1 $\mathrm{mL} / \mathrm{min}$. Injector and mass transfer line temperature were set at 220 and $290{ }^{\circ} \mathrm{C}$, respectively. The oven temperature was programmed from 50 to $150{ }^{\circ} \mathrm{C}$ at 3 ${ }^{\circ} \mathrm{C} / \mathrm{min}$, then held isothermal for $10 \mathrm{~min}$ and finally raised to $250{ }^{\circ} \mathrm{C}$ at $10{ }^{\circ} \mathrm{C} / \mathrm{min}$ Diluted samples $(1 / 100$ $(\mathrm{v} / \mathrm{v})$, in methanol) of $1 \mathrm{~mL}$ were manually injected in the split less mode. The relative percentage of the oil constituents was expressed as percentage by peak area normalization.

Identification of components of the EOLL was based on their retention indices, relative to a homologous series of $\mathrm{n}$-alkane $(\mathrm{C} 8-\mathrm{C} 20)$ on the $\mathrm{ZB}-1$ capillary column under the same operating conditions and computer matching with the Wiley 6.0 libraries, as well as by comparison of the fragmentation patterns of the mass spectra with those reported in the literature data ${ }^{16)}$.

\section{In vitro antioxidant activity}

1) Determination of $\mathrm{DPPH}^{\bullet}$ radical scavenging activity

$\mathrm{DPPH}^{\bullet}$ free radical scavenging activity of EOLLwas estimated using the method of Liyana-Pathirana and Shahid $(2005)^{17)}$ with slight modifications. $100 \mu \mathrm{l}$ of different concentrations (50, 100, 200, 400, $800 \mu \mathrm{g} / \mathrm{mL})$ was added in different test tubes. A solution of 0.1 $\mathrm{mM}$ DPPH in methanol was prepared and $900 \mu \mathrm{l}$ of this solution was added to these tubes, and then shaken vigorously. The tubes were allowed to stand for $20 \mathrm{~min}$ at $27^{\circ} \mathrm{C}$ in dark. The control was prepared as above without any sample. The absorbance of the samples was measured at $517 \mathrm{~nm}$. Radical scavenging activity was expressed as the inhibition percentage of free radicals by the extracts and was calculated by using the following formula:

$\%$ radical scavenging activity $=[$ (absorbance of control 
- absorbance of sample) / absorbance of control] $\times 100$. $\mathrm{IC}_{50}$ was calculated from regression equastion. Quercetin was used as a standard antioxidant. All the concentrations were used in triplicate and the graph was plotted with the mean values.

\section{2) Determination of $\mathrm{ABTS}^{\bullet+}$ radical scavenging activity}

The $\mathrm{ABTS}^{\bullet+}$ radical scavenging activity of different concentration of EOLL was determined according to the procedure described by Re et al. (1999) ${ }^{18)}$ with slight modifications. $\mathrm{ABTS}^{\bullet+}$ was dissolved in water to a 7 $\mathrm{mM}$ concentration. $\mathrm{ABTS}^{\bullet+}$ radical cation was produced by reacting ABTS stock solution with $2.45 \mathrm{mM}$ potassium persulfate (final concentration) and allowing the mixture to stand in the dark at room temperature for $12-16 \mathrm{~h}$ before use. Prior to assay, the solution was diluted with ethanol [about 1:89(v/v)] and equilibrated at $30{ }^{\circ} \mathrm{C}$ to give an absorbance of $0.7 \pm 0.02$ in a $1 \mathrm{~cm}$ cuvette at $734 \mathrm{~nm} 100 \mu \mathrm{l}$ of different concentrations $(50,100,200,400,800 \mathrm{\mu g} / \mathrm{mL})$ of the EOLL was added to $900 \mu \mathrm{ABTS}^{\bullet+}$ free radical solution and incubated for $30 \mathrm{~min}$. OD was taken at exactly $30 \mathrm{~min}$ after the initial mixing. Appropriate solvent blanks were also run in each assay. Radical scavenging activity was expressed as the inhibition percentage of free radicals by the extract and was calculated using the following formula: \% radical scavenging activity $=[$ (absorbance of control-absorbance of sample)/absorbance of control] $\times 100$. Quercetin was used as a standard antioxidant.

\section{3) Super oxide free radical scavenging activity}

The super oxide anion radical protecting activity of EOLL was estimated according to the method Kuthan et al., (1986) ${ }^{19)}$ with slight modification. The reaction mixture contained $0.25 \mathrm{~mL}$ of $0.8 \mathrm{mM}$ xanthine in 0.1 $\mathrm{mM}$ potassium phosphate $(\mathrm{pH} 7.8), 0.15 \mathrm{~mL}$ of $0.5 \mathrm{mM}$ nitro-blue tetrazolium (NBT) in $0.1 \mathrm{mM}$ potassium phosphate $(\mathrm{pH} 7.8)$ and $0.09 \mathrm{~mL}$ of different concentrations of EOLL. After incubation at $25{ }^{\circ} \mathrm{C}$ for $15 \mathrm{~min}$, the reaction was started by adding $0.5 \mathrm{U} / \mathrm{mL}$ xanthine oxidase and reaction mixtures were kept at $25{ }^{\circ} \mathrm{C}$ for $30 \mathrm{~min}$ and after that, by adding $0.5 \mathrm{~mL}$ of $1 \mathrm{~N} \mathrm{HCl}$, reaction of samples was stopped. The absorbance was measured at $560 \mathrm{~nm}$. Quercetin was used as a positive control.

\section{4) Nitric oxide free radical scavenging activity}

At physiological $\mathrm{pH}$, SNP in aqueous solution spontaneously generates nitric oxide ${ }^{20)}$, which interacts with oxygen to produce nitric ions that can be determined by using Greiss reagent. Scavengers of nitric oxide compete with oxygen to minimize the production of nitric oxide. $10 \mathrm{mM}$ of sulphanilamide (SNP) in 0.1 $\mathrm{mM}$ phosphate buffer saline (PBS) was mixed with different concentrations $(50-800 \mu \mathrm{g} / \mathrm{mL})$ of EOLL and incubated at $25{ }^{\circ} \mathrm{C}$ for $150 \mathrm{~min}$. After the completion of incubation period, Greiss reagent A (2\% SNP in $4 \%$ $\left.\mathrm{H}_{3} \mathrm{PO}_{4}\right)$ and Greiss reagent $\mathrm{B}(0.2 \%$ napthyl ethylenediamine dihydrochloride) were added to EOLL + SNP mixture and a further incubated for $10 \mathrm{~min}$. The OD of the chromaphore formed during the diazotization of nitrite with sulphanilamide and subsequent coupling with napthyl ethylenediamine was measured at $540 \mathrm{~nm}$. Quercetin was used as a standard antioxidant.

The percentage of inhibition was measured by the following formula :

$\%$ radical scavenging activity $=[$ (absorbance of control - absorbance of sample) / absorbance of control] $\times 100$. All the tests were performed in triplicate and the graph was plotted with the mean values.

\section{5) Ferric- reducing (FRAP) assay}

The antioxidant activity of EOLL was determined according to Pulido et al. $(2000)^{21)}$. Freshly prepared FRAP reagent $(900 \mu \mathrm{l})$ was added in $30 \mu \mathrm{l}$ of EOLL and incubated in water bath for $30 \mathrm{~min}$ the temperature of water bath was kept at $37{ }^{\circ} \mathrm{C}$. The FRAP reagent contained $2.5 \mathrm{~mL}$ of $20 \mathrm{mM}$ TPTZ in $40 \mathrm{mM} \mathrm{HCl}$ plus $2.5 \mathrm{~mL}$ of $20 \mathrm{mM} \mathrm{FeCl} 3.6 \mathrm{H} 2 \mathrm{O}$ and $25 \mathrm{~mL}$ of $0.3 \mathrm{M}$ acetate buffer, $\mathrm{pH} 3.6$.

\section{MTT assay}

Cell viability in the presence of $\mathrm{H}_{2} \mathrm{O}_{2}$ was determined by MTT bioassay. Briefly, Raw 264.7 macrophage cells $\left(1 \times 10^{6}\right.$ cells/well) were cultured in 96-well plate. After incubation with different concentration of EOLL (200, 400, $800 \mu \mathrm{g} / \mathrm{mL}$ ) for $24 \mathrm{~h}$, cells were challenged with $0.33 \mathrm{mM} \mathrm{H} \mathrm{H}_{2} \mathrm{O}_{2}$ and further incubated for $45 \mathrm{~min}$. After completion of incubation period, $10 \mu \mathrm{l} /$ well of MTT solution $(5 \mathrm{mg} / \mathrm{mL}$ in PBS) was added and plate was incubated for additional $4 \mathrm{~h}$ at $37{ }^{\circ} \mathrm{C}$ to produce the formazan crystals. Finally after the incubation, cells were dissolved in $100 \mu \mathrm{l}$ of DMSO and absorbance was measured in ELISA plate reader (Bio-Tek instrument Co., WA, USA) at $540 \mathrm{~nm}$.

\section{Determination of intra-cellular ROS}

$\mathrm{H}_{2} \mathrm{O}_{2}$ induced ROS (reactive oxygen species) inhibition activity of EOLL was evaluated by using CM-H2DCFDA assay. For this assay, Raw 264.7 macrophage cells $\left(1 \times 10^{6}\right.$ cells/well) were incubated with different concentrations (200, 400, $800 \mathrm{\mu g} / \mathrm{mL})$ of EOLL for $24 \mathrm{~h}$ at $37^{\circ} \mathrm{C}$ in $\mathrm{CO}_{2}$ incubator. After that cells were assaulted with 
$0.33 \mathrm{mM} \mathrm{H}_{2} \mathrm{O}_{2}$ for $45 \mathrm{~min}$. Positive and negative control Raw 264.7 macrophage $\left(1 \times 10^{6}\right.$ cells/well $)$ were

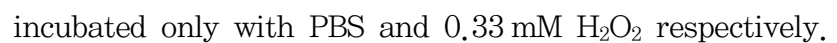
After $45 \mathrm{~min}$ of incubation, cells were trypsinzed, and washed with PBS and cells were incubated for additional $10 \mathrm{~min}$ in presence of $5 \mathrm{mM} \mathrm{CM}-\mathrm{H}_{2} \mathrm{DCFDA}$ dye. The levels of fluorescence intensity were immediately detected by using an EPI fluorescent microscope (Nikon TS 100, JapaN) at $200 \mathrm{X}$ magnification. Quercetin was used as a positive control.

\section{Statistical analysis}

The data were presented as mean \pm SEM $(n=3)$ and analysed using the analysis of variance (ANOVA) procedure of Statistical Analysis System (SPSS, Version 11).

\section{Results}

\section{Chemical composition of essential oil (EOLL)}

Exactly thirty four compounds were identified representing $98.38 \%$ of the total oil (Table 1). EOLL was found to be rich in sesquiterpenes with germacrene D (13.51\%), spathulenol (13.09\%), $\alpha$-cadinol (12.98\%), methoxy-eugenol $(9.76 \%)$, trans-Nerolidol (9.08\%), 10,12-pentacosadiynoicacid $(6.28 \%)$, as main representatives.

\section{Table 1}

Essential oil composition of leaves of $L$. tulipifera.

\begin{tabular}{|c|c|c|c|}
\hline RI & Compound & $\% \mathrm{RA}$ & Indentification \\
\hline 10.88 & a- Hydroxytolvene & 0.98 & RI,MS \\
\hline 11.24 & Eucalyptol & 2.97 & $\mathrm{RI}, \mathrm{MS}$ \\
\hline 11.40 & Santolina triene & 0.36 & RI,MS \\
\hline 11.65 & Cyclopropane & 0.40 & RI,MS \\
\hline 12.27 & $\beta$-Linalool & 2.77 & $\mathrm{RI}, \mathrm{MS}$ \\
\hline 13.90 & $a$-terpineol & 1.04 & $\mathrm{RI}, \mathrm{MS}$ \\
\hline 13.99 & Benzofuran & 0.65 & $\mathrm{RI}, \mathrm{MS}$ \\
\hline 14.84 & Cis -4-Decen-1-ol & 0.94 & RI,MS \\
\hline 15.01 & Trans -4-Decen-1-ol & 0.59 & $\mathrm{RI}, \mathrm{MS}$ \\
\hline 15.23 & Benzenepropanoic acid & 0.87 & $\mathrm{RI}, \mathrm{MS}$ \\
\hline 16.88 & Eugenol me thyl ether & 3.20 & RI,MS \\
\hline 17.30 & Cyclohexane & 2.02 & RI,MS \\
\hline 18.35 & a-Caryophyilene & 0.57 & $\mathrm{RI}, \mathrm{MS}$ \\
\hline 18.75 & Germacrene & 13.51 & $\mathrm{RI}, \mathrm{MS}$ \\
\hline 19.56 & Trans-Nerolidol & 9.08 & $\mathrm{RI}, \mathrm{MS}$ \\
\hline 19.89 & Methox yeugenol & 9.76 & RI,MS \\
\hline 20.15 & Spathulenol & 13.09 & $\mathrm{RI}, \mathrm{MS}$ \\
\hline 20.27 & Caryophyllene oxide & 2.29 & RI,MS \\
\hline 20.95 & 10,12-Pentacosadiynoic acid & 6.28 & RI,MS \\
\hline 21.20 & a-Cadinol & 12.98 & $\mathrm{RI}, \mathrm{MS}$ \\
\hline 21.85 & Trans-Farne sol & 3.72 & RI,MS \\
\hline 23.22 & Isothujol & 1.39 & RIMMS \\
\hline 23.88 & Patchoulane & 2.65 & $\mathrm{RI}, \mathrm{MS}$ \\
\hline 24.34 & $\begin{array}{l}\text { Tans-Z-alphaBisabolene } \\
\text { epox ide }\end{array}$ & 0.58 & $\mathrm{RI}, \mathrm{MS}$ \\
\hline 25.59 & Myristic acid & 2.73 & $\mathrm{RI}, \mathrm{MS}$ \\
\hline 28.45 & 9,12,15-octadecatrien-1-ol & 0.30 & RI,MS \\
\hline 34.33 & Hexadecanoic acid & 0.78 & $\mathrm{RI}, \mathrm{MS}$ \\
\hline \multirow[t]{2}{*}{37.60} & Penta deconoic acid & 1.71 & $\mathrm{RI}, \mathrm{MS}$ \\
\hline & TOTAL & 98.38 & \\
\hline
\end{tabular}

RI, comparison of retention index with bibliography.

a Retention indices relative to n-alkanes C8-C20 on ZB-1 capillar column.

b Relative area (peak area relative to the total peak area).

c Identification: MS comparison of mass spectra with NIST MS libraries.

\section{In vitro antioxidant activity}

\section{1) $\mathrm{DPPH}^{\bullet}$ radical scavenging activity}

The $\mathrm{DPPH}^{\bullet}$ radical is a stable radical with a maximum absorbance at $517 \mathrm{~nm}$ that can readily undergo reduction by the antioxidant molecule. The radical scavenging capacity of EOLL is showed in Fig. 1, expressed as a percentage reduction of the initial DPPH radical absorption by the tested compounds. In this assay, the EOLL at the concentration of $800 \mu \mathrm{g} / \mathrm{mL}$ showed high scavenging of $\mathrm{DPPH}$ radical with a percentage inhibition of $81.62 \%$ ( $\left.\mathrm{IC}_{50} 348.18 \mu \mathrm{g} / \mathrm{mL}\right)$. A significant difference $(p<0.05)$ in the $\mathrm{DPPH}^{\bullet}$ radical scavenging activity was observed at different concentration.

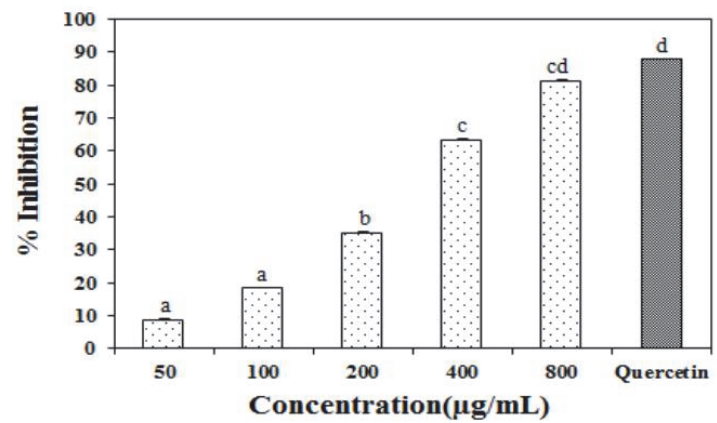

Fig. 1. DPPH ${ }^{\bullet}$ radical scavenging activity of EOLL. Quercetine $(200 \mathrm{\mu g} / \mathrm{mL})$ used as standard compound. (Values are mean of \pm $\mathrm{SD}, \mathrm{n}=3$ ). Values with different superscripts differ significantly from each other $(p<0.05)$.

\section{2) $\mathrm{ABTS}^{\bullet+}$ radical scavenging activity}

Furthermore, the antioxidant capacity of EOLL confirmed by $\mathrm{ABTS}^{\bullet+}$ radical scavenging activity at different concentrations. As demonstrated in Fig. 2, EOLL showed $84.28 \%$ ( $\mathrm{IC}_{50} 330.11 \mu \mathrm{g} / \mathrm{mL}$ ) inhibition at $800 \mu \mathrm{g} / \mathrm{mL}$. EOLL showed a significant $(p<0.05)$ scavenging activity toward ABTS radical cations in a concentration dependent manner, showing a direct role in quenching of free radicals. Standard compound quercetin at 1.25 $\mathrm{g} / \mathrm{mL}$ showed $95.07 \%$ inhibition

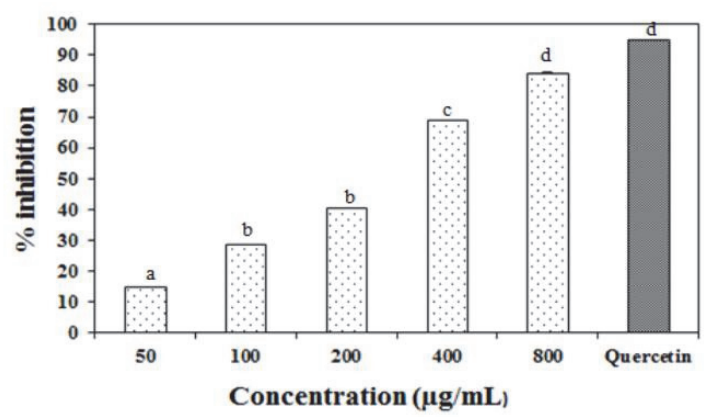

Fig. 2. Determination of $A B T S^{*+}$ free radical scavenging activity of EOLL. Quercetine $(1.25 \mathrm{mg} / \mathrm{mL}$ ) used as standard compound (Values are mean of $\pm S D, n=3$ ). Values with different superscripts differ significantly from each other $(p<0.05)$. 


\section{3) Super oxide free radical scavenging activity}

Superoxide radical protecting activity EOLL measured by the NBT which generates superoxide radicals. As shown in Fig. 3, EOLL showed a significant $(p<0.05)$ inhibition of superoxide free radicals in a concentration dependent manner with $\mathrm{IC}_{50}$ of $243 \mu \mathrm{g} / \mathrm{mL}$, maximum activity of $83.59 \%$ inhibition reported at $800 \mu \mathrm{g} / \mathrm{mL}$ EOLL concentration. Standard compound quercetin showed $96.63 \%$ of inhibition at $20 \mu \mathrm{g} / \mathrm{mL}$.

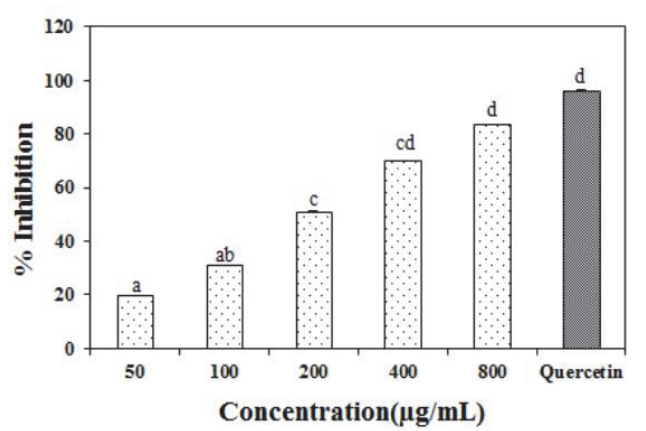

Fig. 3. Effect of EOLL against super oxide free radical scavenging activity. Quercetine $(20 \mathrm{\mu g} / \mathrm{mL})$ used as standard compound (Values are mean of $\pm S D, n=3)$. Values with different superscripts differ significantly from each other $(p<0.05)$.

\section{4) Nitric oxide free radical scavenging activity}

In this study, EOLL reduced the levels of nitrite by competing with oxygen to react with nitric oxide radical, a possible protective effect against oxidative damage. As shown in Fig. 4, EOLL showed most efficient inhibition of nitric oxide radicals with $58.50 \%$ at $800 \mu \mathrm{g} / \mathrm{mL}$ in concentration-dependent manner ( $\mathrm{IC}_{50} 448 \mathrm{\mu g} / \mathrm{mL}$ ). Standard compound, quercetin showed $67.2 \%$ of inhibition at $500 \mu \mathrm{g} / \mathrm{mL}$.

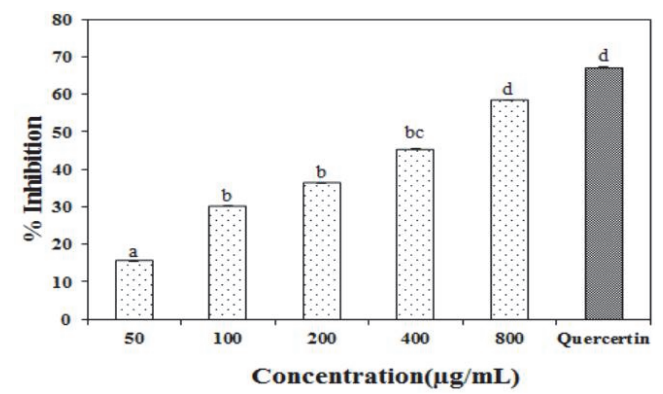

Fig. 4. Nitric oxide free radical scavenging activity of EOLL. Quercetine $(500 \mathrm{\mu g} / \mathrm{mL})$ used as standard compound (Values are mean of $\pm S D, n=3$ ). Values with different superscripts differ significantly from each other $(p<0.05)$.

\section{5) Ferric- reducing (FRAP) assay}

The antioxidant potential of EOLL was examined for its capacity to reduce TPTZ-Fe (III) complex to TPTZ-Fe (II). EOLL showed $1310.484 \mathrm{mM} \mathrm{Fe}$ (II)/g of essential oil ferric reducing capacity. Essential oils containing terpene hydrocarbons and oxygenated terpenes showed antioxidant potential through their reductive capacity TPTZ-Fe (III) complex to TPTZ-Fe (II)(57).

\section{Cyto-protective effect against $\mathrm{H}_{2} \mathrm{O}_{2}-$ induced ROS}

Cytotoxicity modulating activity of EOLL was evaluated on Raw 264.7 macrophage cell survival challenged with $\mathrm{H}_{2} \mathrm{O}_{2}$ which is a strong inducer of oxidative stress with its cytotoxic property in biological system. From Fig. 5, in the absence of EOLL, $\mathrm{H}_{2} \mathrm{O}_{2}$-treated cell survival was reduced to $34.47 \%$ as we supposed $100 \%$ viability in control cells, but cytotoxic effect of $\mathrm{H}_{2} \mathrm{O}_{2}$ was undermined by the pre-incubation with the different concentrations of EOLL $(200,400,800 \mu \mathrm{g} / \mathrm{mL})$ as cell survival was significantly $(P<0.05)$ increased to $40.51,63.38,88.39 \%$ respectively. It showed that EOLL has the potential to reduce $\mathrm{H}_{2} \mathrm{O}_{2}$ induced cytotoxicity due to having antioxidant activity at cellular level.

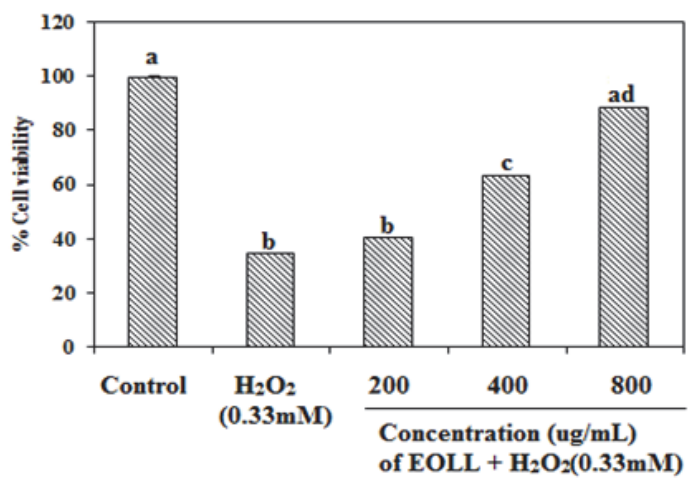

Fig. 5. Has been already changed as per reviewer suggestion. So please add the modified figure in place of the existing figure.

\section{Inhibition of intracellular ROS}

To further explore the mechanism of the protective effect of EOLL on $\mathrm{H}_{2} \mathrm{O}_{2}$-induced oxidative damage in Raw 264.7 macrophage cells, we examined the effect of EOLL on inhibition of intracellular ROS induced by $\mathrm{H}_{2} \mathrm{O}_{2}$ by using $\mathrm{CM}-\mathrm{H}_{2}$ DCFDA stain, which freely can penetrate to cell membranes. After penetrating inside the cells, CM- $\mathrm{H}_{2} \mathrm{DCFDA}$ is hydrolyzed to DCF due to esterase activity and it interacts with free radicals and forms the fluorescent 2', 7'- dichlorofluorescein, which produces green color and is detected by using EPI fluorescence microscope (Nikon TS 100, Japan). As shown in Fig. 6 (A and B), the intracellular elevation of $\mathrm{ROS}$ resulting from $\mathrm{H}_{2} \mathrm{O}_{2}$ exposure was significantly $(p<0.05)$ suppressed by pre-incubation of EOLL at 200, 400, $800 \mu \mathrm{g} / \mathrm{mL}$ in a dose-dependent manner. This showed antioxidant mechanism of EOLL that scavenged from intracellular ROS. 
(A)

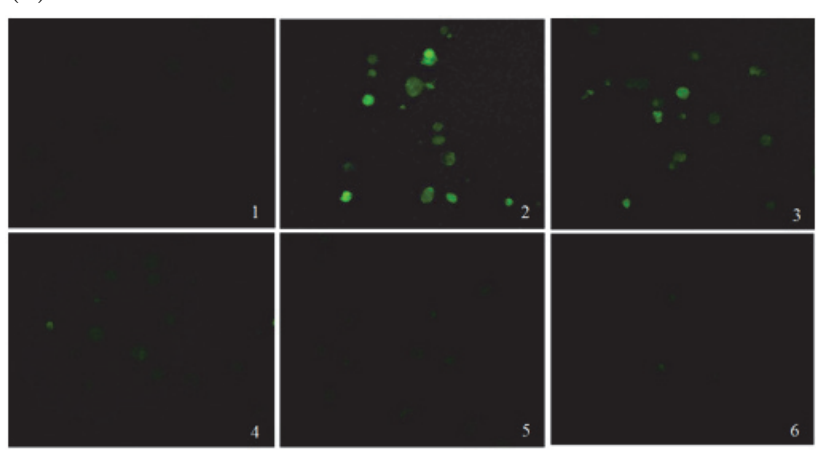

(B)

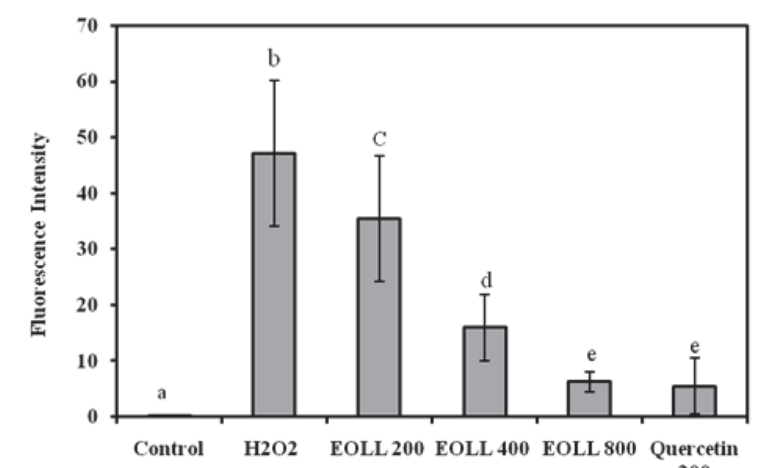

200

Fig. 6. Effect of essential oil isolated from leaves of Liriodendron tulipifera (EOLL) on intracellular ROS induced by treatment of $\mathrm{H} 2 \mathrm{O} 20.33 \mathrm{mM}$ ) in Raw 264.7 macrophage. A. (1) Control; without treatment (2) Only $\mathrm{H}_{2} \mathrm{O}_{2}$ treatment; (3) EOLL $200 \mu \mathrm{g} / \mathrm{mL}+$ $\mathrm{H}_{2} \mathrm{O}_{2}$; (4) $\mathrm{EOLL} 400 \mu \mathrm{g} / \mathrm{mL}+\mathrm{H}_{2} \mathrm{O}_{2}$; (5) $\mathrm{EOLL} 800 \mu \mathrm{g} / \mathrm{mL}+\mathrm{H}_{2} \mathrm{O}_{2}$; (6) Standard compound, Quercetin $200 \mu \mathrm{g} / \mathrm{mL}+\mathrm{H}_{2} \mathrm{O}_{2}$. All images taken by EPI Florescence microscope (Nikon TS 100, Japan) at 200x.

\section{Discussion}

Plant based secondary metabolites such as essential oils are used in the many food industries and generally regarded as safe ${ }^{22)}$. These secondary metabolites posses many biological activities such as antimicrobial, antioxidant, anti-inflammatorty and anticancer ${ }^{23,24)}$. Antioxidants are the substance that protects the body from damage caused by harmful molecules called. synthetic antioxidant such as butylated hydroxyanisole (BHA), butylated hydroxytoluene (BHT) are now suspected due to their potentially harmful and variety of side effect to human health ${ }^{25)}$ as a region an antioxidant substance of natural origins like essential oils are gaining more interest. For this reason the present study was carried out to determine the antioxidant potential of essential oil isolated from $L$. tulipifera L. leaves. In order to determine the chemical composition of $L$. tulipifera leaves essential oil it was subjected to detailed GC/MS analysis. Results showed that it is composed of mainly 34 compounds with abundance of sesquiterpenes with germacrene D (13.51\%), spathulenol (13.09\%) and $\alpha$ -cadinol (12.98\%). In recent years, phenolic compounds, terpenes and their oxygenated phyto-constituents have been reported to have enormous antioxidant and free radical scavenging capacity $^{26)}$. In general, the antioxidant compounds of essential oils are terpenes, which are phenolic in nature, and it would seem rational that their antioxidant mode of action might be related to that of other compounds. Interestingly, the EOLL was also found to rich in sesquiterpenes, which acts as direct free radical scavengers ${ }^{27)}$. Moreover, it stimulates the synthesis of cellular antioxidant enzymes and alleviates cellular damage under elevated oxidative stress conditions ${ }^{28,29)}$.

The antioxidant potential of a substance is primarily evaluated by the $\mathrm{DPPH}^{\bullet}$ assay $^{22)}$. The $\mathrm{DPPH}^{\bullet}$ radical is a stable radical with a maximum absorbance at 517 $\mathrm{nm}$ that can readily undergo reduction by the antioxidant molecule. Consequently, the more rapidly the absorbance decreases, the more potent antioxidant capacity of EOLL observed in terms of hydrogen atom or electron donating ability. In this study we used Quercetin as a reference compounds at the concentration of $200 \mathrm{\mu g} / \mathrm{mL}$ which showed high inhibitory effect on scavenging $\mathrm{DPPH}^{\bullet}$ radical with about $88.03 \%$ and fairly comparable with $800 \mathrm{mg} / \mathrm{mL}$ EOLL. In a similar kind of the study antioxidant potential of Metasequoia glyptostroboides and Iris planifolia (Mill) plant-based essential oils have been proved by using a DPPH assay model for confirmation of antioxidant activity where they found high DPPH scavenging capacity, which warrants the significance of our study and validates the results obtained by us as well ${ }^{30-32)}$.

In the living beings superoxide radicals, a highly toxic species, are continuously produced in metabolic and physiological processes. Superoxide free radicals can generate more toxic and reactive free radicals i.e. hydroxyl radicals or singlet oxygen. Biological molecules such as DNA, lipids and proteins are prominent targets of these oxygen species and cause metabolic and cellular disturbances ${ }^{6)}$. The above mentioned reason provoked us to determine the superoxide radicals scavenging activity of EOLL. On the basis of this assay, we have evidenced that EOLL can quench superoxide free radicals and can terminate radical chain reaction. A research carried out by Chikhi et al., 2012 on essential of Iris planifolia (Mill) also reported the similar kind of result which states that their essential oil potentially sacavenged the superoxide radicals to prove a potent antioxidant activity $^{32)}$. Also, an extensive review by Miguel MG, 2010 explored that those essential oils that efficiently can scavenge the superoxide radical possess a potent 
antioxidant activity is in supports of our finding ${ }^{33)}$.

Nitric oxide radical is a key molecule that involved in several physiological processes such as neural signal transmission, vasodilatation and regulation of blood pressure ${ }^{34)}$. Due to emergence in level of nitric oxide radical during oxidative stress, it becomes the major culprit for numerous carcinomas and inflammatory conditions including arthritis, ulcerative colitis juvenile diabetes, and multiple sclerosis ${ }^{35)}$. During aerobic metabolism, nitric oxide molecule reacts with oxygen molecule and generates intermediates such as $\mathrm{NO}_{2}, \mathrm{~N}_{2} \mathrm{O}_{4}$ and $\mathrm{N}_{3} \mathrm{O}_{4}$. These products are highly genotoxic; causing deamination of purines, pyrimidines and denaturation of enzymes such as DNA ligase and DNA alkyl transferase ${ }^{36)}$. Our results of nitric oxide radical scavenging activity showed that EOLL at $800 \mu \mathrm{g} / \mathrm{mL}$ inhibit $58.5 \%$ of nitric oxide radicals as compare to $67.2 \%$ of standard quercetin at $200 \mu \mathrm{g} / \mathrm{mL}$. The nitric oxide radical scavenging capacities of various plant-based essential oils have been reported previously ${ }^{32,33)}$ and our data designate that EOLL could be an important source of natural nitric oxide radical scavenger.

Antioxidants can be explained as reductants, and neutralizer of pro-oxidants ${ }^{37)}$. Therefore, the antioxidant potential of EOLL was evaluated for its capacity to reduce TPTZ-Fe (III) complex to TPTZ-Fe (II) by donating electron. We observed a positive ferric reducing activity of EOLL and our results are in accordance with previous findings where essential oils extracted from Eucalyptus and Curcuma species showed a positive ferric reducing activity ${ }^{38)}$.

ROS plays a vital role equally in health and disease. The maintenance of low ROS levels is critical to normal cell functions ${ }^{39)}$. Hence a substance that can inhibit intracellular ROS can be very useful in combating many diseases. For this reason we evaluated the role of EOLL in inhibition of intracellular ROS induced by $\mathrm{H}_{2} \mathrm{O}_{2}$. Our findings suggested the dose dependent inhibition of ROS level in the Raw 264.7 macrophages suggesting EOLL a potential candidate as a natural antioxidant.

\section{Conclusion}

In this study, we evaluate the antioxidant and cyto-protective potential of the essential oil isolated from the leaves of $L$. tulipifera L. (EOLL) and further its GC-MS analysis to characterized it.

1. The GC-MS analysis showed the presence of several important phyto-constituents majorly germacrene D, spathulenol, $\alpha$-cadinol, methoxyeugenol, trans-nerolidol, 10,12-Pentacosadiynoicacid. Also, the EOLL was found to exhibit good antioxidant and free radical scavenging capacities.

2. The EOLL was found to exhibit good antioxidant and free radical scavenging capacities in an in vitro examination.

3. Moreover, EOLL showed potent cyto-protecting activity against the $\mathrm{H}_{2} \mathrm{O}_{2}$ by reducing the generation of intracellular ROS.

These experimental evidences proved that EOLL contains bioactive compounds, as sources of natural antioxidants, which might be beneficial to prevent various oxidative stress induced diseases. This study provided the evidence required for the utilization of newly characterized EOLL for its possible use as a source of cost effective natural antioxidant.

\section{References}

1. Porter NA, Caldell SE, Mills KA. Mechanism of free radical oxidation of unsaturated lipids. Lipids. 1995 ; 30 : 277-90.

2. Briviba K, Sies H. Non enzymatic antioxidant defense systems. In: Frei, B. (Ed.), Natural antioxidant in human health and disease. New York : Academic Press. 1994 : 107-28.

3. Ames SN, Shigenaga MK, Hagen TM. Oxidants, antioxidants and degenerative diseases of aging. PNAS. 1993 ; 90(17) : 7915-22.

4. Tavazzi B, Di Pierro D, Amorini AM, Fazzina G, Tuttobene M, Giardina B, Lazzarino G, Energy metabolism and lipid peroxidation of human erythrocytes as a function of increased oxidative stress. Eur J Biochem. 2000 ; 267(3) : 684-9.

5. Florence TM. The role of free radicals in disease. Aust N Z J Ophtalmol. 1995 ; 23(1) : 3-7.

6. Mart i 'nez-Cayuela M. Oxygen free radicals and human disease. Biochimie. 1995 ; 77(3) : 147-61.

7. Schöneich C. Reactive oxygen species and biological aging: A mechanistic approach. Exp Gerontol. 1999 ; 34(1) : 19-34.

8. Young IS, Woodside JV. Antioxidants in health and disease. J Clin Pathol. 2001 ; 54(3) : 176-86.

9. Pardo-Andreu GL, Sanchez-Baldoquin C, Avila-Gonzalez R, Delgado R, Naal Z, Curti C. Fe (III) improves antioxidant and cytoprotecting activities of mangiferin. Eur J Pharmacol. 2006 ; 547 : 31-6.

10. Ito N, Fukushima S, Hasegawa A, Shibata M, Ogiso 
T. Carcinogenicity of butylated hydroxyanisole in F344 rats. J Nat Cancer Inst. 1983 ; 70 : 343-7.

11. Batish DR, Singh HP, Kohli RK, Kaur S. Eucalyptus essential as natural pesticide. For Ecol Manage. $2008 ; 256: 2166-74$.

12. Chen CL, Chang HM. Lignans and aporphine alkaloids in bark of Liriodendron tulipifera. Phytochemistry. $1978 ; 17: 779-82$.

13. Muhammad I, Hufford CD. Phenylpropanoids, sesquiterpenes, and alkaloids from the seeds of Liriodendron tulipifera. J Nat Prod. 1989 ; 52 : 1177-9.

14. Rafinesque CS, Atkinson A. Medical flora, Manual of the medical Botany of the United States of North America. In: Rafinesque, CS, Atkinson, Alexander (Eds.), Alexander, Philadelphia. 1828.

15. Graziose R, Lila MA, Raskin I. Merging traditional Chinese medicine with modern drug discovery technologies to find novel drugs and functional foods. Curr Drug Discov Technol. $2010 ; 7$ : 2-12.

16. Adams RP. Identification of essential oil components by gas chromatography /Quadrupole Mass Spectroscopy. USA : Allured Publishing Corporation, Carol Stream, IL. 2001.

17. Liyana-Pathirana CM, Shahidi F. Antioxidant activity of commercial soft and hard wheat (Triticum aestivum L.) as affected by gastric $\mathrm{pH}$ conditions. J Agric Food Chem. 2005 ; 53 : 2433-40.

18. Re R, Pellegrini N, Proteggente A, Pannala A, Yang M, Rice-Evans C. Antioxidant activity applying an improved ABTS radical cation decolorization assay. Free Radical Biol Med. 1999 ; 26 : 1231-7.

19. Kuthan H, Haussmann HJ, Werringloer JA. Spectrophotometric assay for super-oxide dismutase activities in crude tissue fractions. Biochem J. 1986 ; 237 : 175-80.

20. Marcocci L, Maguire JJ, Droy-Lefaix MT, Packer L. The nitric oxide scavenging properties of Gingobiloba extract EGb 761. Biochem Bioph Res Commun. 1994 ; 15 : 748-55.

21. Pulido R, Bravo L, Saura-Calixto F. Antioxidant of dietary polyphenols as determined by a modified ferric reducing antioxidant power assay. J Agric Food Chem. $2000 ； 46: 3396-402$.

22. Sharma OP, Bhat TK. DPPH antioxidant assay revisited. Food Chem. 2009 ; 113 : 1202-5.

23. Edris AE. Pharmaceutical and therapeutic potentials of essential oils and their individual volatile constituents: A review. Phytother Res. 2007 ; 21 : 308-23.

24. Burt S. Essential oils: Their antibacterial properties and potential applications in foods-A review. Int J Food Microbiol. 2004 ; 94 : 223-53.
25. Amorati R, Foti MC, Valgimigli L. Antioxidant activity of essential oils. J Agric Food Chem. 2013 ; 61(46) : 10835-47.

26. Devasagayam TP, Tilak JC, Boloor KK, Sane KS, Ghaskadbi SS, Lele RD. Free radicals and antioxidants in human health: Current status and future prospects. J Assoc Physicians India. 2004 ; 52 : 794-804.

27. Tamura H, Takasaki A, Taketani T, Tanabe M, Kizuka F, Lee L. The role of melatonin as an antioxidant in the follicle. J Ovarian Res. $2012 ; 5: 5$.

28. Manikonda PK, Jagota A. Melatonin administration differentially affects age-induced alterations in daily rhythms of lipid peroxidation and antioxidant enzymes in male rat liver. Biogerontol. 2012 ; 13 : 511-24.

29. Kharwar RK, Haldar C. Daily variation in antioxidant enzymes and lipid peroxidation in lungs of a tropical bird Perdicula asiatica: role of melatonin and nuclear receptor ROR $\alpha$. Comp Biochem Physiol A Mol Integr Physiol. 2012 ; 162(4) : 296-302.

30. Bajpai VK, Al-Reza SM, Choi UK, Lee JH, Kang SC. Chemical composition, antibacterial and antioxidant activities of leaf essential oil and extracts of Metasequoia glyptostroboides Miki ex Hu. Food Chem Toxicol. 2009 ; 47(8) : 1876-83.

31. Chikhi I, Allali H, Dib MEL, Halla N, Muselli A, Tabti B, Costa J. Free radical scavenging and antibacterial activity of essential oil and solvent extracts of Iris planifolia (Mill) from Algeria. J Med Plants Res. 2012 ; 6 : 1961-8.

32. Miguel MG. Antioxidant and anti-inflammatory activities of essential oils: a short review. Molecules. 2010 ; 15(12) : 9252-87.

33. Dadashpour M, Rasooli I, Sefidkon F, Rezaei MB, Alipour D, Astaneh S. Lipid peroxidation inhibition, superoxide anion and nitric oxide radical scavenging properties of Thymus daenensis and Anethum graveolens essential oils. J Med Plants. 2011 ; 10 : 109-20.

34. Afanasev IB. Signaling functions of free radicals superoxide \& nitric oxide under physiological \& pathological conditions. Mol Biotechnol. 2007 ; 37 : $2-4$.

35. Rabkin SW, Klassen SW. Nitric oxide differentially regulates the gene expression of caspase genes but not some autophagic genes. Nitric Oxide. 2007 ; 16 : 339-47.

36. Lundberg JO, Weitzberg E, Gladwin MT. The nitrate-nitrite-nitric oxide pathway in physiology and therapeutics. Nat Rev Drug Discov. 2008 ; $7(2): 156-67$.

37. Siddhuraju P, Becker K. The antioxidant and free radical scavenging activities of processed cowpea (Vignaunguiculata(L.) Walp.) seed extracts. Food 
Chem. $2007 ; 101:$ 10-9.

38. Shahwar D, Raza MA, Bukhari S, Bukhar G. Ferric reducing antioxidant power of essential oils extracted from Eucalyptus and Curcuma species. Asian Pac J Trop Biomed. 2012 ; 2(3) : S1633-6.

39. Alfadda AA, Sallam RM. Reactive Oxygen Species in Health and Disease. J Biomed Biotech. 2012 ; $2012: 1-14$. 